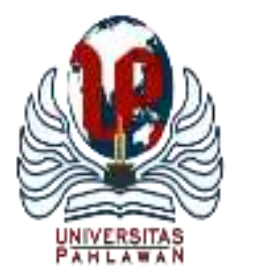

Edukatif : Jurnal Ilmu Pendidikan Volume 4 Nomor 1 Tahun 2022 Halm 879 - 886 EDUKATIF: JURNAL ILMU PENDIDIKAN

Research \& Learning in Education

https:/ledukatif.org/index.php/edukatif/index

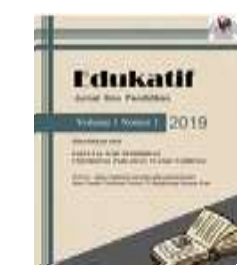

\title{
Pengaruh Kepemimpinan Kepala Sekolah, Tim Kerja, dan Motivasi Kerja terhadap Kepuasan Kerja Guru
}

\author{
Chika Shahnaz $\mathbf{H}^{1 凶}$, Ekawarna ${ }^{2}$, Eddy Haryanto ${ }^{3}$ \\ Universitas Jambi, Indonesia ${ }^{1,2,3}$ \\ E-mail : cshahnaz4@gmail.com¹, ekawarna.unja@yahoo.com², eharyanto@yahoo.com³
}

\begin{abstract}
Abstrak
Latar belakang penelitian guru tidak puas dengan rekan kerja atau tim kerja yang ada disekolah. Tujuan penelitian melihat pengaruh kepemimpinan kepala sekolah, tim kerja, dan motivasi kerja terhadap kepuasan kerja guru. Metode penelitian pendekatan kuantitatif. Hasil penelitian menunjukkan Terdapat pengaruh langsung kepemimpinan kepala sekolah terhadap motivasi kerja guru. Terdapat pengaruh langsung kepemimpinan kepala sekolah terhadap kepuasan kerja guru. Terdapat pengaruh kepemimpinan kepala sekolah secara tidak langsung terhadap kepuasan kerja melalui motivasi kerja guru. Terdapat pengaruh secara langsung tim kerja terhadap motivasi kerja guru. Secara langsung terdapat pengaruh tim kerja terhadap kepuasan kerja guru. Terdapat pengaruh tim kerja secara tidak langsung terhadap kepuasan kerja guru melalui motivasi kerja. Terdapat pengaruh motivasi kerja terhadap kepuasan kerja guru. Kesimpulan penelitian adanya hubungan langsung dan tidak langsung kepemimpinan kepala sekolah, tim kerja dan motivasi kerja terhadap kepuasan kerja guru.
\end{abstract}

Kata kunci: Kepemimpinan Kepala Sekolah, Tim Kerja, Motivasi Kerja dan Kepuasan Kerja Guru.

\section{Abstract}

The background of the research is that teachers are not satisfied with their co-workers or work teams at school. The purpose of this research is to see the influence of principals' leadership, work teams, and work motivation on teacher job satisfaction. The research method used a quantitative approach. The results showed that there was a direct influence of the principal's leadership on the work motivation of teachers. There is a direct influence of the principal's leadership on teacher job satisfaction. There is an indirect influence of the principal's leadership on job satisfaction through teacher work motivation. There is a direct influence of the work team on the work motivation of teachers. There is a direct effect of the work team on teacher job satisfaction. There is an indirect influence of work teams on teacher job satisfaction through work motivation. There is an effect of work motivation on teacher job satisfaction. The research concludes that there is a direct and indirect relationship between principals' leadership, work teams, and work motivation on teacher job satisfaction.

Keywords: Principal Leadership, Team Work, Work Motivation and Teacher Job Satisfaction.

Copyright (c) 2022 Chika Shahnaz H, Ekawarna, Eddy Haryanto

$\triangle$ Corresponding author:

Email : cshahnaz4@gmail.com

DOI $\quad$ : https://doi.org/10.31004/edukatif.v4i1.1987

ISSN 2656-8063 (Media Cetak)

ISSN 2656-8071 (Media Online)

Edukatif : Jurnal Ilmu Pendidikan Vol 4 No 1 Tahun 2022 p-ISSN 2656-8063 e-ISSN 2656-8071 


\section{PENDAHULUAN}

Sekolah merupakan suatu instansi pendidikan yang membutuhkan seorang pemimpin yang dapat memberikan perhatian dalam aspek kepuasan kerja guru. Kepuasan kerja guru merupakan salah satu tanda bahwa instansi pendidikan tersebut dikelola dan dipimpin dengan baik sehingga, dapat menunjang peningkatan kualitas serta mutu pendidikan tersebut. Dengan adanya rasa kepuasan dalam bekerja yang didapatkan para guru maupun pegawai kependidikan lainnya, diharapkan dapat meningkatkan semangat seluruh anggota yang ada di dalam lingkup sekolah tersebut untuk dapat menyelesaikan tugas-tugasnya.

Seperti yang banyak diketahui, guru merupakan salah satu komponen yang memiliki peran yang cukup penting guna berjalannya suatu proses belajar mengajar disekolah. Dalam melaksanakan tugasnya disekolah, guru tidak terlepas dari peran kepemimpinan kepala sekolah. Kepala sekolah sebagai pemimpin tertinggi di lingkungan sekolah tersebut, memiliki peran yang tidak kalah pentingnya dalam memimpin, mengatur, mengawasi, serta mengarahkan para guru dan tenaga kependidikan lainnya. Seperti yang diketahui bahwa kemajuan ataupun kemunduran yang terjadi pada suatu proses belajar mengajar termasuk peran dan tanggung jawab dari kepala sekolah.

Sebagai salah satu komponen pendidikan, guru merupakan salah satu bagian penting yang terlibat dan bersentuhan secara langsung dengan proses pendidikan itu sendiri. Pada hakekatnya, penyelenggaraan dan keberhasilan proses pendidikan pada semua jenjang dan semua satuan pendidikan ditentutukan oleh faktor guru, disamping perlunya unsur-unsur penunjang lainnya. Guru dapat dikatakan sebagai ujung tombak keberhasilan proses pendidikan di sekolah karena melalui kinerja yang ditampilkannya, akan membawa dampak yang signifikan terhadap peningkatan kualitas pendidikan. Untuk itu hal-hal yang mempengaruhi kinerja guru perlu terus dikaji antara lain motivasi kerja, kepuasan kerja, kepemimpinan kepala sekolah dan iklim sekolah (Hosan, Komardi, \& Panjaitan, 2019).

Guru dituntut untuk membawa anak didiknya dalam rangka mencapai tujuan pendidikan melalui interaksi belajar-mengajar. Oleh sebab itu, guru dituntut untuk dapat memiliki kemampuan yang tinggi dalam melaksanakan tugasnya. Namun, seorang guru tidak hanya dituntut dengan berbagai tugas dan kegiatan yang berat tanpa harus diperhatikan tentang kesejahteraan baik dalam bidang material ataupun inmaterial. (Hulmawiyah, Hariani, \& Yudiono, 2018).

Berdasarkan penelitian terdahulu yang peneliti lakukan di dua SMP Negeri yang ada di Kabupaten Tanjung Jabung Barat pada saat peneliti melakukan penelitian akhir jenjang Sarjana, dimana ditemukan guru yang sedikit bercerita bahwa mereka tidak puas dengan kepala sekolah dikarenakan kepala sekolah jarang membantu para guru untuk menyelesaikan masalah yang sedang dihadapi, guru juga mengeluhkan bahwa kepala sekolah memiliki rasa empati yang kurang terhadap keluhan-keluhan guru tersebut. Selain itu, dari hasil wawancara saya terdahulu dengan salah satu guru, terdapat guru yang menyatakan bahwa mereka tidak puas dengan rekan kerja atau tim kerja yang ada disekolah, dikarenakan tim kerja yang kurang solid, suka memilih-milih tim kerja serta memiliki minat yang kurang untuk bekerja bersama tim.

Penelitian yang relevan yaitu tentang analisis pengaruh kepuasan kerja terhadap kinerja guru dengan kepemimpinan kepala sekolah sebagai variabel moderasi (survei pada guru pns di smp negeri 1 jumapolo) yang dilakukan ( DS, Suprayitno, \& Sutarno, 2016).

\section{METODE PENELITIAN}

Adapun kerangka berpikir dari penelitian ini digambarkan pada Paradigma penelitian yang ditunjukkan pada Gambar berikut ini. 
881 Pengaruh Kepemimpinan Kepala Sekolah, Tim Kerja, dan Motivasi Kerja Terhadap Kepuasan Kerja Guru - Chika Shahnaz H, Ekawarna, Eddy Haryanto

DOI: https://doi.org/10.31004/edukatif.v4i1.1987

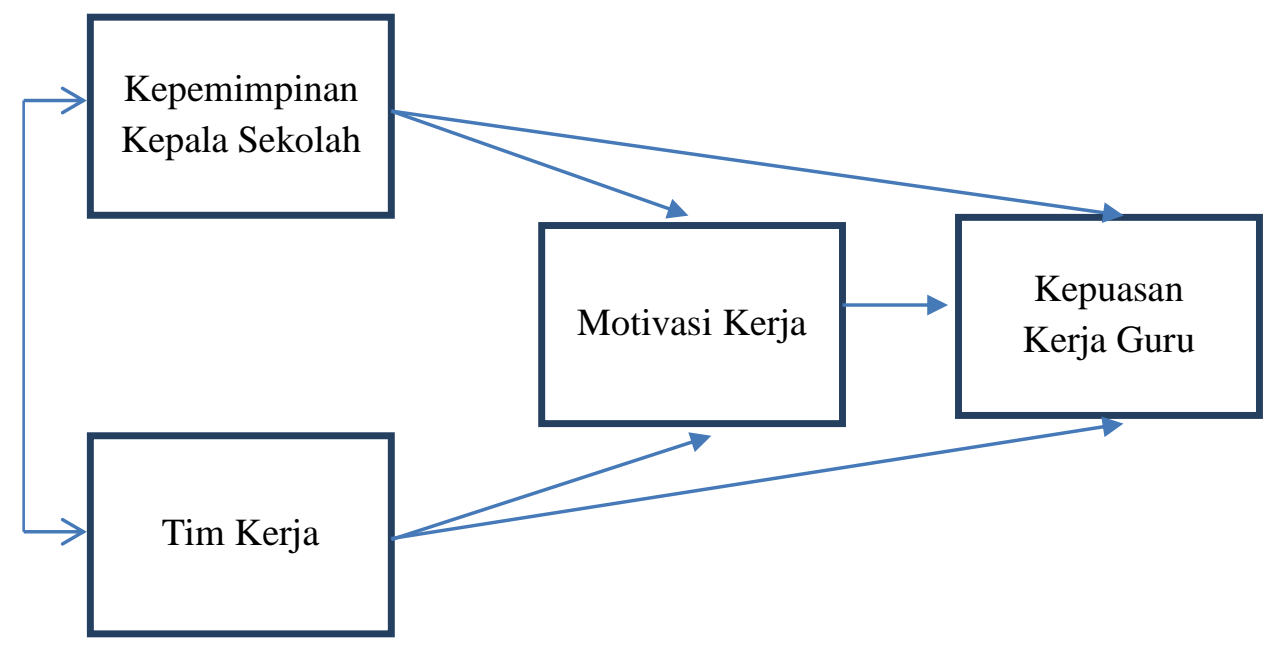

Gambar 1. Paradigma Penelitian

Untuk dapat menguji ada tidaknya peran atau kontribusi variable $\mathrm{X}_{1}$ ( Kepemimpinan), $\mathrm{X}_{2}$ (Tim Kerja), $\mathrm{X}_{3}$ (Motivasi Kerja) dan Y (Kepuasan Kerja Guru), maka Hipotesis yang diajukan dalam penelitian ini adalah:

1. $H_{a 1}$ : Terdapat pengaruh langsung kepemimpinan kepala sekolah terhadap Motivasi Kerja Guru SMP Negeri di Kabupaten Tanjung Jabung Barat

2. $H_{a 2}$ : Terdapat pengaruh langsung kepemimpinan kepala sekolah terhadap Kepuasan Kerja Guru SMP Negeri di Kabupaten Tanjung Jabung Barat

3. $H_{a 3}$ : Terdapat pengaruh tidak langsung kepemimpinan kepala sekolah terhadap Kepuasan kerja melalui Motivasi Kerja Guru SMP Negeri di Kabupaten Tanjung Jabung Barat

4. $H_{a 4}$ : Terdapat pengaruh langsung tim kerja terhadap Motivasi Kerja Guru SMP Negeri di Kabupaten Tanjung Jabung Barat

5. $H_{a 5}$ : Terdapat pengaruh langsung tim kerja terhadap Kepuasan Kerja Guru SMP Negeri di Kabupaten Tanjung Jabung Barat

6. $H_{a 6}$ : Terdapat pengaruh tidak langsung tim kerja terhadap Kepuasan Kerja melalui Motivasi Kerja Guru SMP Negeri di Kabupaten Tanjung Jabung Barat

7. $H_{1 a 4}$ : Terdapat pengaruh langsung Motivasi kerja terhadap Kepuasan Kerja Guru SMP Negeri di Kabupaten Tanjung Jabung Barat

Dalam penelitian ini, peneliti menggunakan pendekatan kuantitatif dengan mengkaji fakta-fakta yang terjadi serta semua data dan informasi diwujudkan dalam bentuk angka, dengan analisis secara statistik. Informasi yang menyangkut variabel dalam penelitian ini diperoleh dari responden yang ditransfer dalam bentuk angka-angka kemudian dianalisis (John. W, 2012). Dengan menggunakan metode deskriptif diharapkan akan memperoleh data yang hasilnya akan diolah dan dianalisis serta akhirnya ditarik sebuah kesimpulan. Kesimpulan yang dibuat dapat berlaku bagi seluruh populasi yang menjadi objek penelitian.

Lokasi yang digunakan adalah SMP Negeri se-Kabupaten Tanjung Jabung Barat. Menurut Wahid (Putra, 2021), data merupakan keterangan atau bahan nyata yang dapat dijadikan dasar kajian (analisis/kesimpulan). Data yang dikumpulkan dapat berupa data primer, yakni data yang diperoleh secara langsung dari sumbernya. Sedangkan data sekunder merupakan data yang diperoleh dari informasi yang telah diolah oleh pihak lain, seperti segala macam bentuk dokumen. Data primer ini diperoleh melalui hasil angket kepemimpinan kepala sekolah, tim kerja, motivasi kerja dan kepuasan kerja guru.

Populasi dalam penelitian adalah guru SMP Negeri sebanyak 786 orang. Pemilihan populasi guru SMP Negeri merupakan objek pokok dalam penelitian ini. Menurut Arikunto, "Populasi adalah keseluruhan subjek penelitian, yang berkaitan dengan penelitian yang akan dilakukan". Populasi dalam penelitian ini berjumlah 
882 Pengaruh Kepemimpinan Kepala Sekolah, Tim Kerja, dan Motivasi Kerja Terhadap Kepuasan Kerja Guru - Chika Shahnaz H, Ekawarna, Eddy Haryanto

DOI: https://doi.org/10.31004/edukatif.v4i1.1987

786 orang. Sampel yang digunakan dalam penelitian ini merupakan sebagian dari jumlah populasi guru SMP Negeri di Tanjung Jabung Barat yang berjumlah 786 orang dari 58 sekolah negeri, sampel yang dipakai dari berbagai guru dengan jenis kelamin dan umur yang berbeda-beda.

Penggumpulkan data mengunakan angket dan dokumen. Membuat angket pertanyaan-pertanyaan tertulis yang kemudian nantinya akan dijawab oleh responden atau sampling. Dokumen disini digunakan untuk memperoleh data tentang data guru. Penelitian menggunakan SEM untuk melakukan analisis jalur semua variable. Teknik analisa data pada penelitian ini menggunakan teknik personally administered questionnaires, yaitu kuesioner disampaikan dan dikumpulkan langsung oleh peneliti. Pada penelitian ini data diuji dan diukur dengan memakai pendekatan kuantitiatif dengan pendekatan Analisis jalur Partial Least Square (PLS).

\section{HASIL DAN PEMBAHASAN PENELITIAN}

Dalam penelitian ini, karakteristik dari responden dilihat dari jenis kelamin serta usia. Responden dari penelitian ini berjumlah 197 responden, dimana untuk jenis kelamin laki-laki berjumlah 77 orang, dan untuk jenis kelamin perempuan berjumlah 120 responden. Untuk usia, yang berusia kurang dari 40 tahun berjumlah 67 responden, usia 40 sampai dengan 50 tahun berjumlah 84 responden dan untuk usia yang lebih dari 50 tahun berjumlah 46 responden.

Untuk melihat kinerja dari masing masing variable penulis mengunakan teknik IPMA analisis. Analisis matriks kinerja-kepentingan (IPMA) memberikan teknik tambahan bagi peneliti untuk memperkaya Analisis PLS-SEM, dan dengan demikian memperoleh hasil tambahan (Ringle, C. M \& Sarstedt, M, 2016). IPMA Mengambil kinerja dari setiap konstruksi memperhitungkan dan membedakan efek total model struktural (dimensi kepentingan). Juga, kinerja rata-rata dari setiap variabel laten menyoroti faktor penentu penting untuk peningkatan praktik manajemen (Hair, Hult, G. T. M, Ringle, C, \& Sarstedt, M., 2017). IPMA memprioritaskan konstruksi untuk meningkatkan konstruksi target tertentu. IPMA memperoleh efek total dari hubungan konstruksi lainnya yaitu, variabel Kepemimpinan, Tim Kerja, Motivasi dan Kepuasan Kerja (Ringle, C. M \& Sarstedt, M, 2016). Kinerja dari masing-masing variabel dalam penelitian ini ditampilkan pada tabel 4.17 serta gambar 4.3 berikut ini.

Tabel 1

Pemetaan masing-masing Variabel

\begin{tabular}{lc}
\hline Variabel & Kinerja LV \\
\hline Kepemimpinan Kepala Sekolah & 54,147 \\
\hline Kepuasan Guru & 57,784 \\
\hline Motivasi Kerja & 53,859 \\
\hline TIM KERJA & 54,181 \\
\hline
\end{tabular}




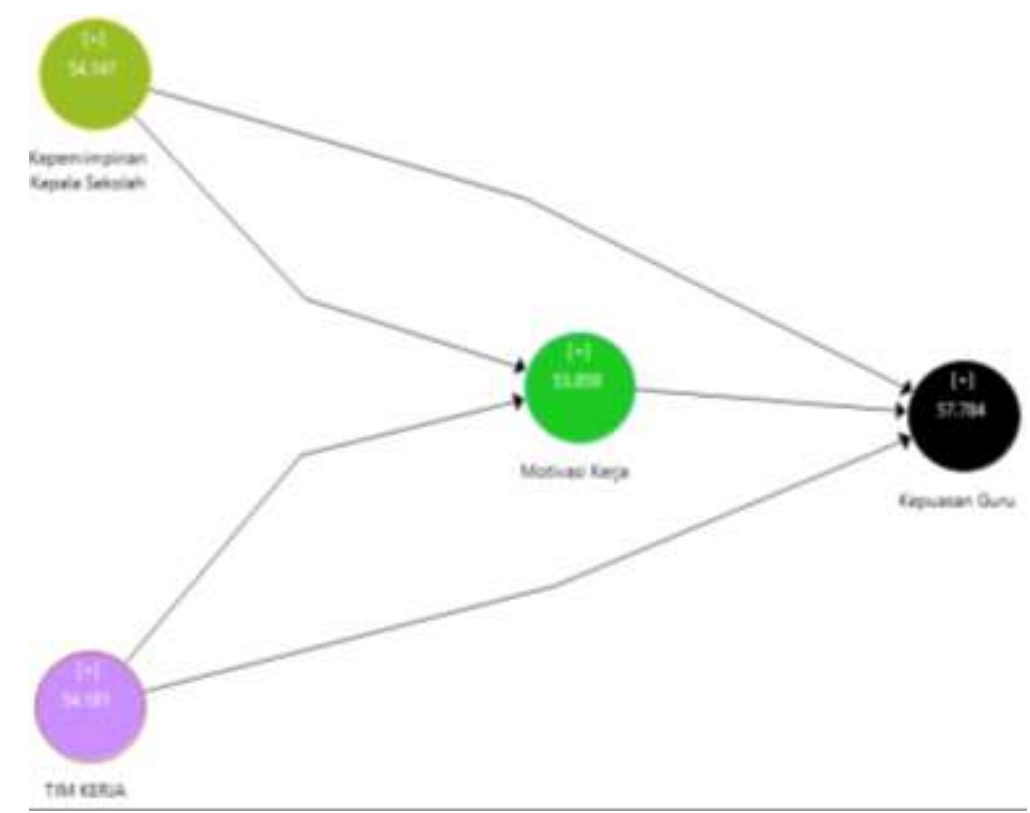

\section{Gambar 2. Pemetaan masing-masing Variabel}

Pada gambar 2. Pemetaan masing-masing Variabel di atas dapat dijelaskan bahwa Pemetaan masih dapat dilihat dari angka yang tertera di dalam kolom tersebut di mana dapat dilihat kinerja dari variabel Motivasi nya masih rendah dibandingkan variabel yang lain, artinya guru belum merasa begitu termotivasi dengan kondisi yang ada, perlu perbaikan yang artinya juga motivasi mereka harus ditingkatkan dengan peran pemimpin dan Tim kerja yang dirasa mampu meningkatkan motivasi. Selanjutya, dibandingkan dengan variabel yang lain di mana kinerja dari kepeimimpinan yaitu sebesar $54 \%$ dan variabel tim kerja juga memiliki kinerja sebesar 54\% jadi kinerja dari variabel yang tertinggi yaitu pada variabel Kepuasan Kerja Guru artinya Guru sudah merasa puas dengan tim kerja dan kepemimpinan yang ada mampu memberikan mereka motivasi dan juga menigkatkan kepuasan mereka sehingga ada perasaan cinta terhadap pekerjaannya sehingga variabel ini cukup baik. Kemudian juga, terdapat variabel yang perlu ditingkatkan yaitu, variabel motivasi tentunnya dengan penggunaan IPMA yang dapat memberikan kita informasi untuk memetakan mana variabel yang perlu ditingkatkan.

Hipotesis pertama menguji Apakah Pengaruh Kepemimpinan Kepala Sekolah terhadap Motivasi Kerja. Hasil pengujian menunjukkan bahwa ada pengaruh yang signifikan. Dimana nilai p Value dibawah 0,05 hipotesis pertama diterima. Hal tersebut membuktikan bahwa Kepemimpinan Kepala sekolah memiliki pengaruh dengan Original Sample sebesar 0,350 (35,0\%).

Hipotesis kedua menguji Apakah terdapat pengaruh Kepemimpinan Kepala Sekolah terhadap Kepuasan Kerja Guru. Secara P Values positif artinya terdapat pengaruh Kepemimpinan terhadap Kepuasan. Hasil pengujian menunjukkan bahwa ada pengaruh yang signifikan. Dimana nilai $p$ Value dibawah 0,05 hipotesis Kedua diterima. Hal tersebut membuktikan bahwa Kepemimpinan berpengruh terhadap Kepuasan kerja dengan Original Sample sebesar 0,730 (73,0\%).

Penelitian ini sejalan dengan penelitian-penelitian yang dilakukan oleh Suwar, dengan judul "Hubungan Persepsi Guru Terhadap Kepemimpinan Kepala Sekolah dengan Motivasi Kerja dan Kepuasan Kerja”. Hasil penelitian ini menunjukkan bahwa: a. Ada hubungan positif antara persepsi guru terhadap kepemimpinan kepala sekolah dengan motivasi kerja guru $r=0,742$. Sedangkan $F=100,189$ dan $p=0,000$. b. Ada hubungan yang positif antara persepsi guru terhadap kepemimpinan kepala sekolah dengan kepuasan kerja guru diperoleh $\mathrm{r}=0,524$ dan $\mathrm{F}=31,024$ dan $\mathrm{p}=0,000$. 
884 Pengaruh Kepemimpinan Kepala Sekolah, Tim Kerja, dan Motivasi Kerja Terhadap Kepuasan Kerja Guru - Chika Shahnaz H, Ekawarna, Eddy Haryanto

DOI: https://doi.org/10.31004/edukatif.v4i1.1987

Hipotesis ketiga menguji Apakah terdapat pengaruh Tidak Langsung Kepemimpinan Kepala Sekolah terhadap Kepuasan Kerja melalui Motivasi Kerja Guru. Hasil pengujian menunjukkan bahwa ada pengaruh yang signifikan. Dimana nilai p Value dibawah 0,05 hipotesis Ketiga diterima. Hal tersebut membuktikan bahwa Terdapat pengaruh siginfikan dengan Original Sample sebesar 0,023 (2,3\%).

Hipotesis keempat menguji Apakah terdapat pengaruh langsung Tim Kerja terhadap Motivasi Kerja Guru. Hasil pengujian menunjukkan bahawa ada pengaruh yang signifikan. Dimana nilai p Value dibawah 0,05 hipotesis Keempat diterima. Hal tersebut membuktikan pengaruh dengan Original Sample sebesar 0,401 $(40,1 \%)$.

Hipotesis kelima menguji apakah terdapat pengaruh langsung Tim Kerja terhadap Kepuasan Kerja Guru. Hasil pengujian menunjukkan bahwa ada pengaruh yang signifikan. Dimana nilai p Value dibawah 0,05 hipotesis Kelima diterima. Hal tersebut membuktikan pengaruh dengan Original Sample sebesar 0,13,9 $(13,9 \%)$.

Hasil penelitian ini sejalan dengan penelitian terdahulu yang di lakukan oleh (Saragih, 2011) yang mengemukakan bahwa terdapat pengaruh langsung tim kerja dengan kepuasan kerja guru, semakin baik tim kerja maka semakin baik juga kepuasan kerja guru. Kepuasan Kerja guru tergantung dengan kondisi lingkungan tempat kerja terutama rekan kerja yang nyaman. Menurut (Ginting, 2019) Kerja tim berpengaruh langsung terhadap kepuasan kerja guru, semakin baik kerjasama tim semakin tinggi kepuasan kerja guru.

Hipotesis keenam menguji Apakah terdapat pengaruh tidak langsung Tim Kerja terhadap Kepuasan Kerja melalui Motivasi Kerja Guru. Hasil pengujian menunjukkan bahwa ada pengaruh yang signifikan. Dimana nilai $\mathrm{p}$ Value dibawah 0,05 hipotesis Keenam diterima. Hal tersebut membuktikan bahwa pengaruh siginfikan dengan Original Sample sebesar 0,027 (2,7\%).

Hasil penelitian ini sejalan dengan penelitian yang dilakukan oleh Hadi tentang pengaruh iklim organisasi dan motivasi mengajar terhadap kinerja guru SMK, SMK, MA Muhamadiyah di Kabupaten Kudus, diperoleh kesimpulan bahwa pengaruh variabel iklim organisasi (X1) dan variabel motivasi mengajar (X2) terhadap kinerja profesional guru (Y) sebesar 0,73 atau 73,0\%. Angka ini menunjukan bahwa kinerja guru (Y) secara bersama-sama (simultan) dipengaruhi oleh variabel iklim organisasi (X1) dan variabel motivasi mengajar (X2) sebesar 73,0\%.

Hipotesis ketujuh menguji Apakah terdapat pengaruh langsung Motivasi terhadap Kepuasan Kerja Guru. Secara P Values positif artinya terdapat pengaruh langsung Motivasi terhadap Kepuasan Kerja Guru SMP Negeri di Kabupaten Tanjung Jabung Barat. Hasil pengujian menunjukkan bahwa ada pengaruh yang signifikan. Dimana nilai p Value dibawah 0,05 hipotesis Ketujuh diterima. Hal tersebut membuktikan pengaruh dengan Original Sample sebesar 0,066 (6,6\%).

Hal ini sejalan dengan penelitian Titin Eka Ardiana judul tesis Pengaruh Motivasi Kerja Guru Terhadap Kinerja Guru Akuntansi SMK di Kota Ponorogo. Penelitian memakai metode survei, teknik pengumpulan data memakai angket yang selanjutnya dianalisis memakai regresi sederhana dan regresi berganda dengan dibantu SPSS Versi 20. Hasil penelitian memperlihatkan bahwa motivasi kerja guru berpengaruh positif terhadap kinerja guru akuntansi dengan kontribusi sebesar 80,6\%, selebihnya 19,4\% ditentukan oleh faktor lain diluar penelitian.

Keterbatasan temuan dan makna penelitian terhadap perkembangan keilmuan yaitu secara operasional, fokus penelitian ini dibatasi dalam empat variabel penelitian yakni kepempinan kepala sekolah, tim kerja, motivasi kerja, dan kepuasan kerja guru smp negeri di kabupaten tanjung jabung barat.

\section{KESIMPULAN}

Dalam Penelitian ini terdapat variabel bebas yang terdiri dari kepemimpinan kepala sekolah X1, Tim Kerja X2, Motivasi kerja guru X3, dan variabel Kepuasan Kerja Y. Berdasarkan analisis hasil penelitian dan pembahasan yang telah diuraikan sebelumnya maka dapat disimpulkan yaitu Terdapat pengaruh langsung 
885 Pengaruh Kepemimpinan Kepala Sekolah, Tim Kerja, dan Motivasi Kerja Terhadap Kepuasan Kerja Guru - Chika Shahnaz H, Ekawarna, Eddy Haryanto

DOI: https://doi.org/10.31004/edukatif.v4i1.1987

kepemimpinan kepala sekolah terhadap motivasi kerja guru SMPN di Kabupaten Tanjung Jabung Barat. Ini berarti bahwa kepemimpinan kepala sekolah memiliki pengaruh yang baik terhadap motivasi kerja guru, semakin baik kepemimpinan kepala sekolah dapat meningkatkan motivasi kerja guru. Terdapat pengaruh langsung kepemimpinan kepala sekolah terhadap kepuasan kerja guru SMPN di Kabupaten Tanjung Jabung Barat. Ini berarti bahwa kepemimpinan kepala sekolah memiliki pengaruh yang baik terhadap kepuasan kerja guru, semakin baik kepemimpinan kepala sekolah, maka akan semakin meningkatkan kepuasan kerja guru. Terdapat pengaruh kepemimpinan kepala sekolah secara tidak langsung terhadap kepuasan kerja melalui motivasi kerja guru SMPN di Kabupaten Tanjung Jabung Barat. Hal ini dapat diartikan bahwa kepemimpinan yang baik dengan memotivasi kerja guru secara tidak langsung akan menimbulkan serta meningkatkan kepuasan kerja bagi guru. Terdapat pengaruh secara langsung tim kerja terhadap motivasi kerja guru SMPN di Kabupaten Tanjung Jabung Barat. Hasil penelitian ini menunjukan bahwa dalam bekerja sesama rekan mempunyai peran yang sangat penting dalam meningkatkan motivasi kerja guru. Secara langsung terdapat pengaruh tim kerja terhadap kepuasan kerja guru SMP Negeri di Kabupaten Tanjung Jabung Barat. Hal ini diartikan, semakin baik tim kerja maka semakin baik juga kepuasan kerja guru. Kepuasan Kerja guru tergantung dengan kondisi lingkungan tempat kerja terutama rekan kerja yang nyaman. Terdapat pengaruh tim kerja secara tidak langsung terhadap kepuasan kerja guru melalui motivasi kerja guru SMP Negeri di Kabupaten Tanjung Jabung Barat. Hal ini diartikan bahwa, tim kerja melalui motivasi kerja guru secara tidak langsung dapat meningkatkan kepuasan kerja guru. Terdapat pengaruh motivasi kerja terhadap kepuasan kerja guru SMP Negeri di Kabupaten Tanjung Jabung Barat. Hal ini diartikan bahwa motivasi dapat meningkatkan kepuasan kerja guru.

\section{UCAPAN TERIMA KASIH}

Terimakasih kepada bapak Prof. Dr. Drs. Ekawarna, M. Psi selaku Dosen pembimbing I dan bapak Eddy Haryanto., M. Sc. Ed., Ph. D selaku Dosen pembimbing II. TIM penguji, Dosen, dan Staf pengelola Pascasarjana Universitas Jambi. Terima kasih kepada Edukatif: Jurnal Ilmu Pendidikan Universitas Pahlawan yang telah bersedia menerbitkan jurnal.

\section{DAFTAR PUSTAKA}

DS, R., Suprayitno, \& Sutarno. (2016). Analisis Pengaruh Kepuasan Kerja terhadap Kinerja Guru dengan Kepemimpinan Kepala Sekolah sebagai Variabel Moderasi (Survei pada Guru PNS di SMP Negeri 1 Jumapolo). Jurnal Ekonomi dan Kewirausahaan, 16(1).

Abidah, Hidayatullah, Simamora, Fehabutar, \& Mutakinati. (2020). The Impact of Covid-19 to Indonesian Education and Its Relation to the Philosophy of "Merdeka Belajar. Studies in Philosophy of Science and Education, 1(1).

Alwi, A. F. (2010). Pola Pembinaan dan Pengawasan Kepala Sekolah dalam Meningkatkan Disiplin dan Kinerja Guru SMP Negeri Sekecamatan Ketungau Hulu Kabupaten Sintang.

Amran. (2013). Pengaruh Disiplin Kerja Terhadap Kinerja Pegawai Kantor. Departemen Sosial Kabupaten Gorontalo, Jurnal Ichsan Gorontalo, 4(2).

Ginting, A. K. (2019). Pengaruh Supervisi Akademik, Kerjasama Tim dan Locus of Control Terhadap Kepuasan Kerja Guru SMA Negeri di Kota Binjai . (Doctoral dissertation, UNIMED).

Hadiati, E. (2018). Pengaruh Disiplin Kerja terhadap Kinerja Guru Mts se-Kota Bandar Lampung. Al-darah E-jurnal Kependidikan Islam, 8.

Hair, Hult, G. T. M, Ringle, C, \& Sarstedt, M. (2017). A Primer on Partial Least Squares Structural Equation Modeling (PLS-SEM). . SAGE Publications. 
886 Pengaruh Kepemimpinan Kepala Sekolah, Tim Kerja, dan Motivasi Kerja Terhadap Kepuasan Kerja Guru - Chika Shahnaz H, Ekawarna, Eddy Haryanto

DOI: https://doi.org/10.31004/edukatif.v4i1.1987

Harli, T. (2012). Pembelajaran Aktif dan Berpusat Pada Siswa Sebagai Jawaban atas Perubahan Kurikulum dan Pelaksanaan Pembelajaran di Sekolah Dasar. Yogyakarta: Widyaiswara LPMP.

Hosan, Komardi, D., \& Panjaitan, H. P. (2019). Pengaruh Motivasi Kerja, Budaya Sekolah dan Kepemimpinan Kepala Sekolah terhadap Kepuasan Kerja dan Kinerja Guru di Sekolah Metta Maitreya Pekanbaru. Jurnal Ilmiah Manajemen, 7(3).

Hulmawiyah, Hariani, L. S., \& Yudiono, U. (2018). Pengaruh Kepemimpinan Kepala Sekolah, Disiplin Kerja, dan Kompensasi terhadap Kepuasan Kerja Guru. Jurnal Riset Pendidikan Ekonomi, 3(1).

John. W, C. (2012). Research Design Pendekatan Kualitatif, Kuantitatif, dan Mixed. Yogyakarta: Pustaka Pelajar.

Kusnan. (2004). Analisis Sikap Iklim Organisasi, Etos Kerja Dan Disiplin Kerja dalam Menentukan Efektivitas Kinerja Organisasi di Garnisun Tetap III. Program Pascasarjana Universitas Airlangga.

Mulyani, \& Jamilus. (2021). Pengembangan Pendidik Sebagai Sumber Daya Manusia di Sekolah Menengah Atas. Edukatif: Jurnal Ilmu Pendidikan, 3(4), 1170 - 1176. https://edukatif.org/index.php/edukatif/index

Nurrohma, R. I., \& Adistana, G. A. (2021). Penerapan Model Pembelajaran Problem Based Learning dengan Media E-Learning Melalui Aplikasi. Edukatif: Jurnal Ilmu Pendidikan, 3(4). https://doi.org/10.31004/edukatif.v3i4.544

Pebrianto, Herpratiwi, \& Fitriawan, H. (2021). Pengembangan Multimedia Pembelajaran Hari Raya Agama Buddhadi Sekolah Minggu Buddhis Bodhisattva. Edukatif: Jurnal Ilmu Pendidikan, 3, 1261 - 1270. Retrieved from https://edukatif.org/index.php/edukatif/index

Putra, F. (2021). Pengaruh Pengetahuan Kewirausahaan, Lingkungan Keluarga dan Ekspektasi Pendapat terhadap Minat Berbisnis Online Mahasiswa Pendidikan Ekonomi Universitas Jambi. Jambi: Tesis Magister Pendidikan Ekonomi.

Qolb, S. K., \& Hamami, T. (2021, Universitas Pahlawan tuanku Tambusai Riau). Impelementasi Asas-asas Pengembangan Kurikulum terhadap Pengembangan KurikulumPendidikan Agama Islam. EDUKATIF: JURNAL ILMU PENDIDIKAN, 3(4), 1120 - 1132. doi:https://edukatif.org/index.php/edukatif/index

Rahmawati, T., \& Daryanto. (2013). Penilaian Kinerja Profesi Guru dan Angka Kreditnya. Yogyakarta: Gava Media.

Ringle, C. M, \& Sarstedt, M. (2016). Gain More Insight from Your PLS-SEM Results: The ImportancePerformance Map Analysis, Industrial Management \& Data Systems. 116(9).

Rizal, A. S. (2019). Pengaruh Motivasi Kerja dan Kedisiplinan terhadap Kinerja Guru SMP. Ulul Albab, 3, $15-22$.

Saragih, R. P. (2011). Pengaruh Persepsi Guru Tentang Kepemimpinan Kepala Sekolah, Tim Kerja Dan Kepuasan Kerja Terhadap Komitmen Organisasi (Studi Empiris Di SMK Pariwisata Kota Medan) . Doctoral dissertation, UNIMED.

Sopaheluakan, N. (2020, Juli). Hubungan antara Kepemimpinan Kepala Sekolah dan Budaya Kerja dan Kinerja Guru SMA Negeri 1 Seram Barat Kabupaten Seram. Jurnal Edukatif Ilmu Pendidikan, 9(3), 5062.

Wahid, I. A. (2016). Pengaruh Motivasi, Etos Kerja dan Disiplin Kerja Terhadap Kinerja Pegawai Negeri Sipil (Pns) Pada Dinas Kehutanan dan Perkebunan Daerah Kabupaten MorowalI. Jurnal Katalogis, Volume 4 Nomor 8, Agustus 2016 hlm 156-163, 4. Retrieved from https://media.neliti.com > media > publications

Yusuf, R. N., Musyadad, V. F., Iskandar, Y. Z., \& Widiawati, D. (2021). Implikasi Asumsi Konsep Diri Dalam Pembelajaran Orang Dewasa. Edukatif : Jurnal Ilmu Pendidikan, 3(4).

https://doi.org/10.31004/edukatif.v3i4.513 